MESTRADO EM TEMAS DE PSICOLOGIA

NEUROCOGNIÇĀO E LINGUAGEM

The Effects of Visual Movement on Beatbased vs. Duration-based Temporal Perception

Nathércia Lima Torres

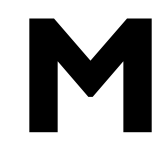

2018

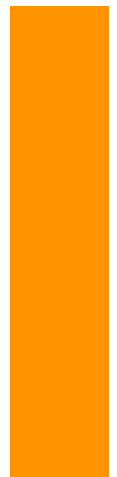


Universidade do Porto

Faculdade de Psicologia e de Ciências da Educação

\title{
THE EFFECTS OF VISUAL MOVEMENT ON BEAT-BASED VS. DURATION- BASED TEMPORAL PERCEPTION
}

\author{
Nathércia Lima Torres
}

Junho 2018

Dissertação apresentada no Mestrado em Temas de Psicologia, Faculdade de Psicologia e de Ciências da Educação da Universidade do Porto, orientada pela Doutora Susana Silva (FPCEUP) e coorientada pela Professora Doutora Maria de São Luís de Vasconcelos Fonseca e Castro Schöner (FPCEUP). 


\begin{abstract}
AVISOS LEGAIS
O conteúdo desta dissertação reflete as perspectivas, o trabalho e as interpretações do autor no momento da sua entrega. Esta dissertação pode conter incorreções, tanto conceptuais como metodológicas, que podem ter sido identificadas em momento posterior ao da sua entrega. Por conseguinte, qualquer utilização dos seus conteúdos deve ser exercida com cautela.
\end{abstract}

Ao entregar esta dissertação, o autor declara que a mesma é resultante do seu próprio trabalho, contém contributos originais e são reconhecidas todas as fontes utilizadas, encontrando-se tais fontes devidamente citadas no corpo do texto e identificadas na secção de referências. $\mathrm{O}$ autor declara, ainda, que não divulga na presente dissertação quaisquer conteúdos cuja reprodução esteja vedada por direitos de autor ou de propriedade industrial. 


\begin{abstract}
It is known that moving visual stimuli (bouncing balls) hold an advantage over static visual ones (flashes) in sensorimotor synchronization, such that the former match auditory beeps in driving synchronization, while the latter do not. This occurs in beat-based synchronization, but not in beat-based purely perceptual tasks, suggesting that the advantage is action-specific. The main goal of this study was to test for the advantage of moving over static visual stimuli in a different perceptual timing system - duration-based perception, so as to determine if the advantage is action-specific in a broad sense, i.e., if it excludes both beat-based and duration-based perception. We asked a group of participants to perform different tasks with three stimulus types: auditory beeps, visual bouncing balls (moving) and visual flashes (static). First, participants performed a duration-based perception task in which they judged whether intervals were speeding up or slowing down, followed by a synchronization task with isochronous sequences. Then they performed a beat-based perception task in which they judged whether sequences sounded right or wrong. Balls outperformed flashes and matched beeps in synchronization. In the durationbased perceptual task, there were no stimulus type effects, while in beat-based perception beeps outperformed balls and flashes. Our findings suggested that the advantage of moving over static visual stimuli is grounded on action rather than perception in a broad sense, in that it is absent in both beat-based and duration-based perception.
\end{abstract}

Keywords: audition; beat; timing systems, synchronization, vision 


\section{RESUMO}

A sincronização com estímulos visuais em movimento (e.g., bolas a saltar) é mais eficaz que a sincronização com estímulos visuais estáticos (e.g., flash, ou imagem estática intermitente), e os primeiros são tão eficazes como os estímulos auditivos (bipes) enquanto os segundos não são. A vantagem dos estímulos visuais em movimento ocorre na sincronização com uma batida, mas não em tarefas de perceção temporal envolvendo uma batida, sugerindo que se trata de uma vantagem específica da ação. Neste estudo, testámos se a vantagem dos estímulos visuais em movimento ocorre num sistema percetual diferente, envolvendo durações absolutas. Um grupo de participantes foi submetido a diferentes provas, utilizando três tipos de estímulos: bipes (auditivos), bolas (visuais) em movimento e bolas (visuais) estáticas e intermitentes. As provas foram divididas em três fases: (1) Perceção da duração (intervalos a acelerar ou a atrasar), (2) Sincronização com estímulos isócronos, (3) Perceção baseada em batidas (sequências corretas ou incorretas). Os resultados da sincronização reforçaram a evidência de que as bolas em movimento são mais eficazes que bolas estáticas, e tão eficazes como os bipes. Na perceção baseada em durações, não houve efeito do estímulo, enquanto que, na perceção baseada em batidas, os bipes superaram tanto as bolas em movimento quanto as estáticas. Os resultados sugerem que a vantagem dos estímulos visuais em movimento em relação aos estímulos visuais estáticos é, num sentido amplo, específica da sincronização, visto que esta vantagem está ausente nos dois sistemas de perceção temporal (duração e batida).

Palavras chave: audição, batida, perceção temporal, sincronização, visão 


\section{Introduction}

From microseconds to circadian rhythms, the perception of time is crucial in human life. The development of different mechanisms to quantify time along a wide range of durations is an essential skill in many facets of social behavior, such as playing music, speaking, and performing a sport (Merchant \& Lafuente, 2008).

Previous research has identified two different timing systems, defining how the underlying timing circuitry of the brain might work (McCauley \& Jones, 2003; Pashler, 2001; Yee, Holleran, \& Jones, 1994). The first is duration-based timing, which refers to the absolute duration of individual time intervals. Under this mechanism, time is encoded like a stopwatch (Teki, Grube, Kumar, \& Griffiths, 2011). The second system concerns relative time or beat-based timing. It engages an implicit regular pulse that marks equallyspaced events in time, providing a unit reference for measuring time (Grahn, 2012). The existence of duration-based and beat-based timing systems is supported by neuroimaging studies. Teki et al (2011) conducted a functional magnetic resonance imaging (fMRI) experiment, in which participants were asked to compare the duration of the last interval to the penultimate interval, while varying the rhythmic context of preceding intervals to be regular (beat-based) or irregular (duration-based). The authors observed that the olivocerebellar system mediates duration-based timing, while the striato-thalamo-cortical system assists beat-based timing. The existence of beat-based and duration-based mechanisms is also supported by behavioral studies (MacAuley \& Jones, 2003; Pashler, 2001).

Modality effects are known to exist in beat-based perception as well as in beatbased sensorimotor synchronization (synchronization hereafter) - the execution of movements in time with an external stimulus (Pollok, Krause, Butz, \& Schinitizler, 2009; Repp, 2005). These modality effects indicate that beat-based performance is influenced by the modality (auditory vs. visual) in which temporal patterns are presented (Granh, 2012). In the perceptual domain, several studies have reported that auditory stimuli such as beeps are perceived more accurately than visual ones such as flashing images (Glenburg \& Jona, 1991; Grahn, 2012; Grahn, Henry, \& Mcauley, 2011; Guttman, Gilroy, \& Blake, 2005; Patel, Iversen, Chen, \& Repp, 2005; Repp \& Panel, 2002; Stauffer, Haldemman, Troche, \& Rammsayer, 2012). Beyond the perceptual domain, the investigation of modality differences in synchronization performance has also shown the advantage of audition over 
vision (Chen, Repp, \& Patel, 2002; Hove, Fairhurst, Kotz \& Keller, 2013; Patel et al., 2005; Pollok, Krause, Butz, \& Schinitzler, 2009). In order to account for these results, it has been suggested that audition would hold an advantage against vision in generating a sense of beat.

Recent studies challenged the idea that visual beat-based processing is always poor, and they did it by showing that visual stimuli with apparent motion (e.g., moving bars, bouncing balls) outperform static visual stimuli (flashes) in synchronization (Gan, Huang, Zhou, Qian, \& Wu, 2015; Hove, Spivey, \& Krumhansl, 2010; Iversen, Patel, Nicodemus, \& Emmorey 2015). By increasing the realism of the visual motion trajectory, both Gan et al (2015) and Silva \& Castro (2016) went even further and demonstrated that synchronization with a bouncing ball is no less stable than synchronization with an auditory metronome. In other words, this investigation demonstrated that synchronization with moving visual stimuli can be as effective as synchronization with auditory ones, but synchronization with static visual stimuli cannot. The idea of interaction between Modality (visual vs. auditory) and Continuity (moving vs. static visual stimuli) on synchronization corresponds to these effects. The word "Continuity" has been proposed by Hove and colleagues (2013) to designate both the opposition between moving (bouncing balls, continuous presence on screen) and static (flashes, discrete/discontinuous presence) visual stimuli, and that between continuous (siren) and discrete (beep) sounds. In the present paper, we focused only on the visual modality, where "Continuity" means movement.

The reason why visual stimuli need movement (bouncing balls vs. static flashes) to compete with auditory ones (beeps) is not well determined. One possibility is that the lower temporal resolution of vision requires an increased reliance on spatial information in order to better perceive the stimulus (Hove et al., 2013). Nevertheless, the advantage of visual moving over visual static stimuli (flashes) seems to be synchronization-specific, given the lack of evidence of this advantage in the perceptual domain. For instance, even though it seems possible to extract a beat from visual stimuli ( $\mathrm{Su}, 2014)$, the perceptual processing of visual stimuli may rely on auditory recoding (Grahn et al., 2011), while the reverse is not true (visual recoding of auditory stimuli). Critically, Silva et al. (2016) demonstrated recently that bouncing balls match beeps within synchronization, but not within perception, providing direct evidence that the advantage of moving visual over static visual beat-based visual stimuli is action-specific, and thus remains absent in purely perceptual tasks. 
Although there have been great advances in the investigation of modality effects in timing, the advantages of moving over static visual stimuli (Modality x Continuity interactions) have not been fully explored. For instance, the vast majority of studies in timing evaluate only the beat-based mechanism, and an interesting question remains to be addressed: What is the advantage of moving over static visual stimuli, if any, in durationbased processing? We know that the advantage is present in beat-based synchronization, but absent in beat-based perception. Is it also absent in duration-based perception?

The main goal of this investigation was comparing Modality $\mathrm{x}$ Continuity interactions across beat-based vs. duration-based perception. Our main motivation was to better understand the advantage of moving over static visual stimuli in temporal processing. In addition, the comparison across timing systems would also contribute to test further the hypothesis of distinct sensorimotor networks for beat-based and duration-based timing (Grube, Lee, Griffiths, Barker, Woodruff 2010; MacAuley \& Jones, 2003; Pashler, 2001, Teki et al., 2011).

Our secondary interest - and subsidiary to the main one - was to replicate previous findings of Modality x Continuity in synchronization by Silva et al. (2016), which were found for beat-based synchronization (balls matched beeps, unlike flashes) but not for beat-based perception (balls underperformed beeps, paralleling flashes).

In order to achieve our goals, we carried out a behavioral study where a single group of participants performed beat-based synchronization, a beat-based perceptual task and a duration-based perceptual task - the latter two under the paradigm of forced-choice detection. In each of these three tasks (beat-synchronization, beat perception and duration perception), participants were tested with optimal/moving (bouncing balls) vs. nonoptimal/static visual (flash) and optimal auditory (beeps) stimuli. Thus, when referring to Modality (vision vs. audition) x Continuity interactions, we are only considering Continuity levels for the visual modality, not for the auditory one. Our analysis focused on the comparisons of bouncing balls with beeps and flashes with beeps.

In the synchronization task, we expected to replicate Silva et al.'s (2016) findings. This means that we expected balls to outperform flashes and to be effective enough to match beeps, even without using a spatial trajectory with rectified sinusoidal velocity related to gravity such as Gan et al. (2015) did. Instead, we made the ball squash when hitting the lowest vertical point, thus generating the impression of collision. This has been done in Silva et al. (2016), who saw an advantage of bouncing balls over flashes, and an equivalence between balls and beeps. 
In the beat-based perception task, we also expected to replicate Silva et al.'s (2016) findings, which showed no Modality x Continuity interactions but, rather, a Modality effect (both balls and flashes underperformed beeps).

Concerning the comparison between beat-based and duration-based perception, there could be two scenarios: Either the Modality x Continuity interaction would change according to the perceptual timing system - showing up in duration-based perception but not in beat-based perception, or the interaction would be absent in the two timing systems. In the former case, Modality x Continuity interactions could be related to part of the brain networks subtending duration-based processing, and new hypotheses on the origins of this effect could be raised. In the latter case, no new cues would be provided for the origins of this "powerful ball effect" (see Silva et al., 2016), except that these origins lie outside the perceptual system in a broad sense (beat and duration-based perception). 


\section{Material and Method}

\section{Participants}

Forty-five participants (11 men) took part in the experiment. Ages ranged between 18 and 32 years $(M=20.62, S D= \pm 2.67)$, and schooling between 14 and 18 years. They had normal or corrected-to-normal vision, and they were free from psychiatric, neurological, motor and hearing disorders. All participants but six were right-handed. Sixteen had had formal music training beyond elementary school curricula, but only seven for more than three years (3: 5 years; $2: 7$ years; 1: 8 years; 1: 10 years). They all signed informed consent according to the Declaration of Helsinki.

\section{Stimuli}

Visual sequences (Flashes, Balls) consisted of videos at 30 frames per second, and auditory sequences (Beeps) of 16 bit mono audio files at $44.1 \mathrm{kHz}$ sampling frequency. Stimulus details are next described, for the three levels of Stimulus Type. Beep: there were short $(67 \mathrm{~ms})$ sinusoidal tones $(\mathrm{F} 0=450 \mathrm{~Hz})$. Flash: short $(67 \mathrm{~ms})$ flashes of a static blue ball $\left(2.1^{\circ}\right.$ diameter) centered over a black background. Bouncing ball: the same ball bouncing on an imaginary ground (squashing at the lower point of the trajectory). The spatial trajectory of the bouncing ball was linear.

In the duration-based perception task, we tested participants' abilities in judging whether a sequence of intervals seemed to be either speeding up or slowing down. For that purpose, we created 16 sequences of two intervals (three events), in which half of them were speeding up and half slowing down. In speed up sequences, the second interval was $566 \mathrm{~ms}, 300 \mathrm{~ms}, 167 \mathrm{~ms}, 133 \mathrm{~ms}$, or $34 \mathrm{~ms}$ shorter than the first one (Appendix 1). In slow down sequences, the second interval was $566 \mathrm{~ms}, 167 \mathrm{~ms}, 133 \mathrm{~ms}$, or $34 \mathrm{~ms}$ larger than the first. Therefore, for each value of interval shortening in speed up versions (e.g., -133 ms) there was an equal enlarge in slow down versions $(+133 \mathrm{~ms})$. The reason why we created two modalities (speed up vs. slow down) was to prevent possible biases: for instance, slow down sequences could look more natural for bouncing balls. Therefore, we decided to explore two opposite modes. 
In the beat-based synchronization task, sequences were isochronous and included 48 events (beep onset, flash onset, bouncing ball hitting the ground) with inter-onsetintervals (IOS) of $600 \mathrm{~ms}$ (beat length). In the beat-based perception task, we tested participants' abilities in judging whether sequences of isochronous intervals (600 ms) ending with shorter intervals sounded "right" (correct sequences, ending with $300 \mathrm{~ms}$ intervals, integer fraction of the beat) or "wrong" (incorrect sequences, ending with $300 \pm$ $133 \mathrm{~ms}$ intervals, non-integer fraction). For this task, we created 8 correct sequences with length ranging from $4200 \mathrm{~ms}$ ( 7 beats) to $6000 \mathrm{~ms}$ (10 beats). Correct sequences presented a series of whole beats ending either with two half-beats (stimuli 1-4, see Appendix 2) or only with one half-beat (stimuli 5-8). Incorrect sequences were derived from correct ones by adding or subtracting $133 \mathrm{~ms}$ to either one or two intervals in the terminal part of the sequence.

Half of the incorrect sequences were designed so that the probe interval started on time and had an incorrect length (300 $\pm 133 \mathrm{~ms}$ type 1 deviation), and the other half had a probe interval started out of time and had also an incorrect length (type 2 deviation). Type 1 deviations included one incorrect interval, while type 2 deviations included two. The four type 1-deviation sequences included two shortened probe intervals (300-130 ms) and two enlarged interval $(300+130 \mathrm{~ms})$; the same went for type 2-deviation sequences. The reason why we created two deviation types was twofold. First, we needed different sequences for the eight trials and this would be difficult to achieve by varying sequence length only. Second, we wanted to maximize the indices of discrimination across Stimulus Type levels, and the response to deviation types seemed to be a good approach.

\section{Procedure}

We ran the experiment on E-prime 2 (https://pstnet.com/products/e-prime/). Participants sat 55cm away from a Samsung Syncmaster 957DF monitor, with a Roland SPD-8 MIDI drum pad sideways (side of the dominant hand). First, they performed the duration-based temporal perception task, then the synchronization task, and lastly the beatbased temporal perception task.

In the duration-based perception task, they were asked to judge whether each of the 16 sequences $(8+8)$ was either speeding up or slowing down, by pressing key ' 1 ' or ' 2 ' on the computer keyboard. We showed them one example of each stimulus type (ball, beep and flash) speeding up and slowing down, and then clarified possible doubts. In the 
synchronization task, participants were instructed to use a stick for tapping along with the stimulus for as long as it lasted. The audio signals generated by tapping the drum pad were recorded in an audio file whose onset was locked to the onset of the stimulus. Participants wore headphones in all tasks - in the auditory ones to listen to the stimuli, and in the visual ones to minimize any noise from outside the room. In the beat-based perception task, they were asked to judge whether each of 16 sequences $(8+8)$ was correct or incorrect by pressing key ' 1 ' or ' 2 ' on the computer keyboard. We told them that correct versions should sound/look like someone was walking and then start to walk faster, while incorrect versions should sound/look like someone suddenly started to walk with a limp. Sequence presentation was randomized across participants and Stimulus Types. They went through all Stimulus Types (ball, beep, flash) in each task before proceeding to the next task.

The three Stimulus Types were ordered in four different ways: beep-ball-flash, beep-flash-ball, ball-flash-beep and ball-flash-beep. For each of these four orders, we created two conditions in the perception task: one in which the left key (' 1 ') meant correct and another where it meant incorrect, and one which the left key ('1') meant speed up and another where it meant slow down. Each participant was assigned to one of these eight conditions (four orders x two keys). Half of the participants performed auditory first, and the other half visual first.

At the end of the experimental session, participants were given a questionnaire on strategies that they might have used, namely relying on recoding of visual stimuli or viceversa.

\section{Data preprocessing and statistical analysis}

In line with recent studies in the field (Gan et al., 2015; Hove et al., 2013; Iversen, 2015; Silva \& Castro, 2016), the tapping time series from the synchronization task were analyzed applying circular statistics method (Fisher, 1993) as implemented in the Circstats toolbox for Matlab (Berens, 2009). The audio files generated by participants in the synchronization task (their taps) were first analyzed with software Praat (http://www.fon.hum.uva.nl/praat/). Tap onsets were detected with the function "annotateto text grid (silences)", which determines the onset and offset of silent vs. sounding periods in the audio files. Since synchronization typically requires a few taps to stabilize, the first two seconds of the sequence were discarded from analysis, and so were deviant intervals (longer than $1000 \mathrm{~ms}$ and shorter than $200 \mathrm{~ms}$ ). Synchronization performance was 
quantified in three ways. In the first measure, we computed the mean asynchronies of taps relative to beats. Asynchronies were represented in terms of relative phase: each tap was mapped onto a circular unit ranging from $-\pi$ to $\pi$. Zero values mean perfect alignment to the beat. Negative values $(0$ to $-\pi)$ indicate the tap preceded the beat and positive values $(0$ to $+\pi$ ) indicate the tap followed the beat. Mean asynchronies correspond to the mean relative phase per subject. In the second measure, we assessed synchronization stability, which is also based on asynchronies. In circular statistics, synchronization stability is described the $\mathrm{R}$ index. $\mathrm{R}$ indexes the regularity of the tap-to-target coordination, on a unit circle ranging from 0 (unstable tapping with uniformly distributed relative phases) to 1 (perfect stable tapping with a unimodal distribution of relative phases). At last, we measured the error correction for period, as indexed by lag 1 autocorrelation for Inter-TapIntervals. The negative value of the lag-1-autocorrelation means that a longer interval tends to be followed by a shorter one, which is can be taken as a sign of online error correction (Iversen et al., 2015). The three measures were analyzed with repeated-measures ANOVAs with Stimulus Type as within-subjects factor. The ANOVA was followed by crossstimulus comparisons in case of interaction, using paired-samples t-tests, Bonferronicorrected for multiple comparisons.

Performance in the perception tasks (discrimination between speed up and slow down; right and wrong) was approached with d-prime measures (Stanislaw \& Todorov, 1999). We used repeated-measures ANOVAs with Timing System (duration-based vs. beat-based) and Stimulus Type (ball, beep, flash) as factors. As a planned comparison, we then analyzed Stimulus Type effects on duration-based and beat-based separately, followed by paired-samples t-tests comparing Stimulus Type levels. In the duration-based task, we further analyzed the Change Direction (speed up vs. slow down, see Appendix 1) $\mathrm{x}$ Stimulus Type interaction. In the beat-perception task, we analyzed the effects of Deviation Type (type 1 vs. type 2, see Appendix 2) x Stimulus Type on accuracy for incorrect targets (correct rejections).

To investigate further the association/dissociation of Timing Systems, we tested the correlation between performance in duration-based and beat-based systems. Lastly, we tested the correlation of synchronization performance with perceptual discrimination in the two Timing Systems (duration and beat-based) in order to get additional results concerning the relation between production and perception.

Even though we had few participants with musical training and training was relatively modest, we wanted to rule out any effects of musical experience. Musical 
experience is known to influence rhythmic performance, specifically synchronization skills (Chen, Penhune, \& Zatorre, 2008). To that purpose, we tested if the years of musical training correlated either with synchronization and perceptual discrimination. 


\section{Results}

\section{Synchronization}

\subsection{Mean direction of Asynchronies}

The mean direction of asynchronies was negative for all conditions. Negative values indicated that the taps occurred before the beat, and that there was anticipating behavior consistent with beat-based timing (Figure 1). There was no significant effect of Stimulus Type, $F(2,88)=2.969, p=.074 ; \eta^{2}=.63$.

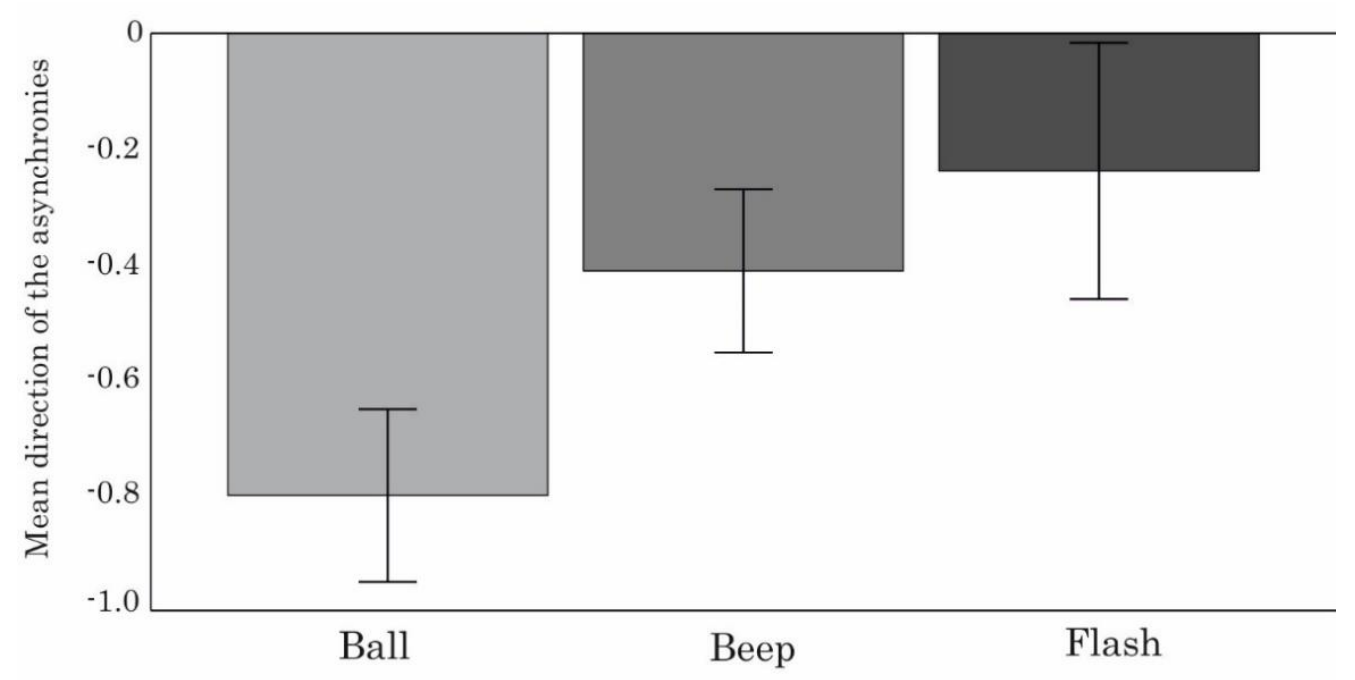

Figure 1. Mean direction of tap-beat asynchronies (represented as relative phases) as a function of Stimulus Type (auditory - beep; moving visual - ball; static visual - flash).

\subsection{Stability of Synchronization}

The ANOVA for stability of synchronization showed a significant effect of Stimulus Type, $F(2,88)=24.482, p<.001 ; \eta_{p}^{2}=.357$. Cross-stimulus comparisons showed non-significant differences between balls and beeps, $t(44)=0.310, p=.756$; the remaining comparison yielded significant differences between beeps and flashes, $t(44=$ $5.771, p<.001 / .003$ (uncorrected/corrected $p$ ), $d=1.11$, and balls and flashes, $t(44)=$ 6.102, $p<.001 / .003, d=1.08$. Thus, beeps and balls were equivalent in driving synchronization stability, and both outperformed flashes (Figure 2). 


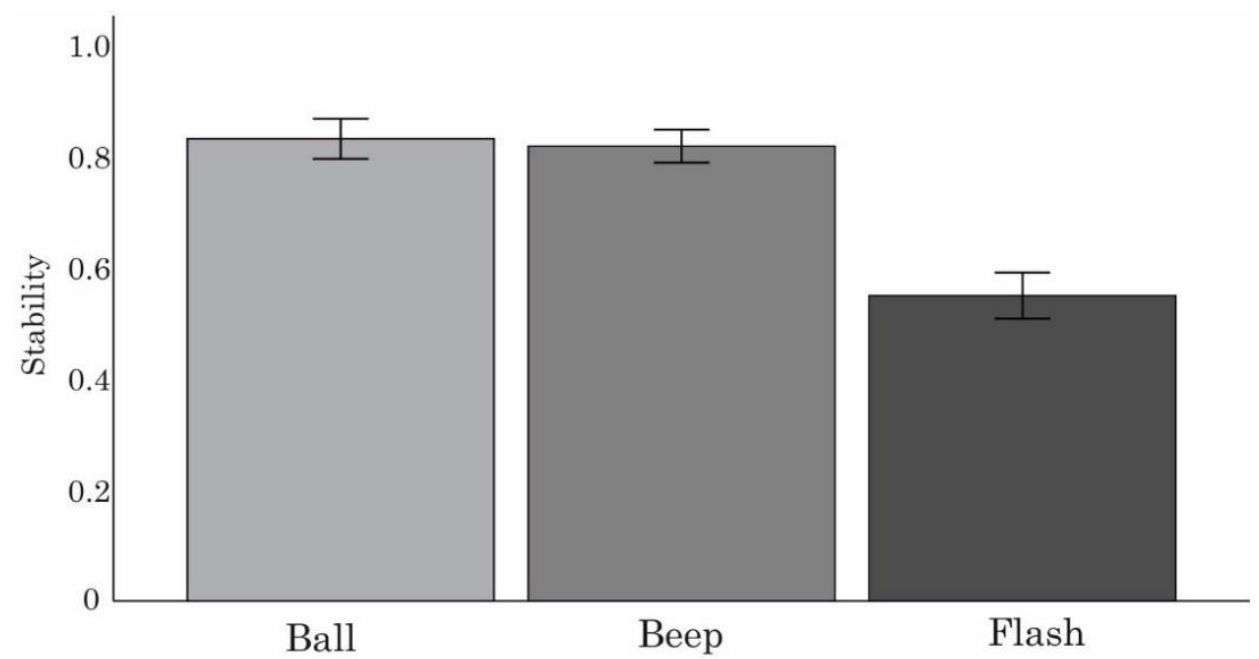

Figure 2. Synchronization stability as function of Stimulus Type (auditory - beep; moving visual - ball; static visual - flash).

\subsection{Lag-1 autocorrelation}

There was a significant effect of Stimulus Type, $F(2,82)=7.853, p=.001, \eta_{p}^{2}=$ .161. Beeps and balls presented negative values (larger for balls), implying that subjects corrected their own errors, whereas flashes showed positive ones, suggesting perseverance of the error (Figure 3). Comparisons across the three conditions indicated a significant difference between balls and flashes, $t(41)=-4.439, p<.001 / .003, d=0.40$; the remaining comparisons yielded non-significant results [balls vs. beeps: $t(41)=-1.513, p=.138$; beeps vs. flashes: $t(42)=-2.493, p=.017 / .051]$.

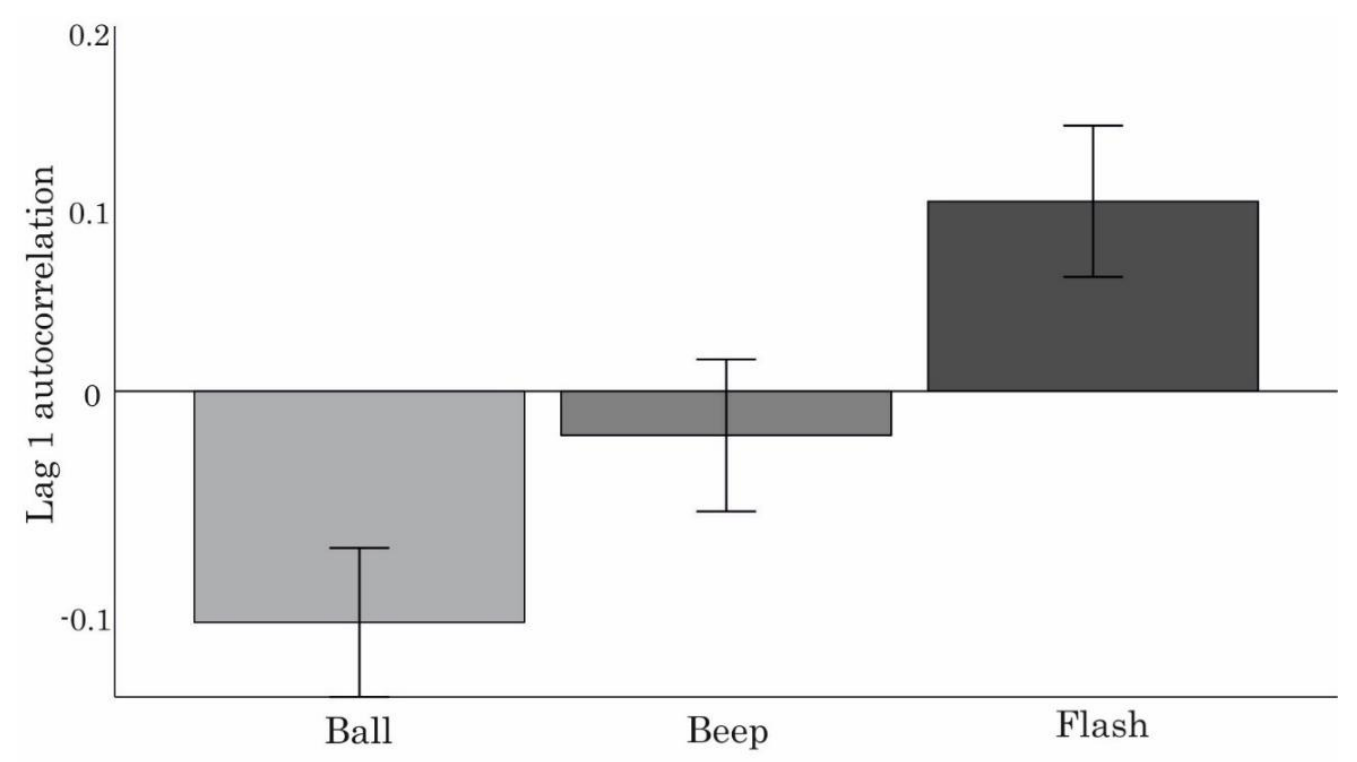

Figure 3. Lag 1 autocorrelation as a function of Stimulus Type (auditory - beep; moving visual - ball; static visual - flash). 


\section{Perception}

\subsection{Discrimination (d-prime)}

D-prime values differed significantly from zero in all conditions (all $p$ s $<.003$ ). The interactive effect of Stimulus Type and Timing System on d-prime was marginal, $F(2,88)$ $=2.682, p=.074, \eta_{p}^{2}=.057$. The effect of Stimulus Type on duration-based perception was non-significant, $F(2,88)=0,259, p=.77, \eta_{p}^{2}=.006$, but it was significant for beatbased perception, $F(2,88)=7,473, p=.001, \eta^{2}=.145$ (Figure 4). In the duration-based condition, there were no significant differences among the three stimuli [balls vs. beeps, $t(44)=-.706, p=.484$; balls vs. flashes, $t(44)=-.268, p=.790$; beeps vs. flashes, $t(44)=$ $.444, p=.660]$, while in the beat-based condition, beeps outperformed balls and flashes, and balls yielded no significant differences compared to flashes [beeps vs. flashes, $t(44)=$ $3.664, p=.001 / .003, d=.60$; balls vs. beeps, $t(44)=-2.532, p=.015 / .045, d=.46$; balls vs. flashes, $t(44)=.813, p=.271($ Figure 4$)$.

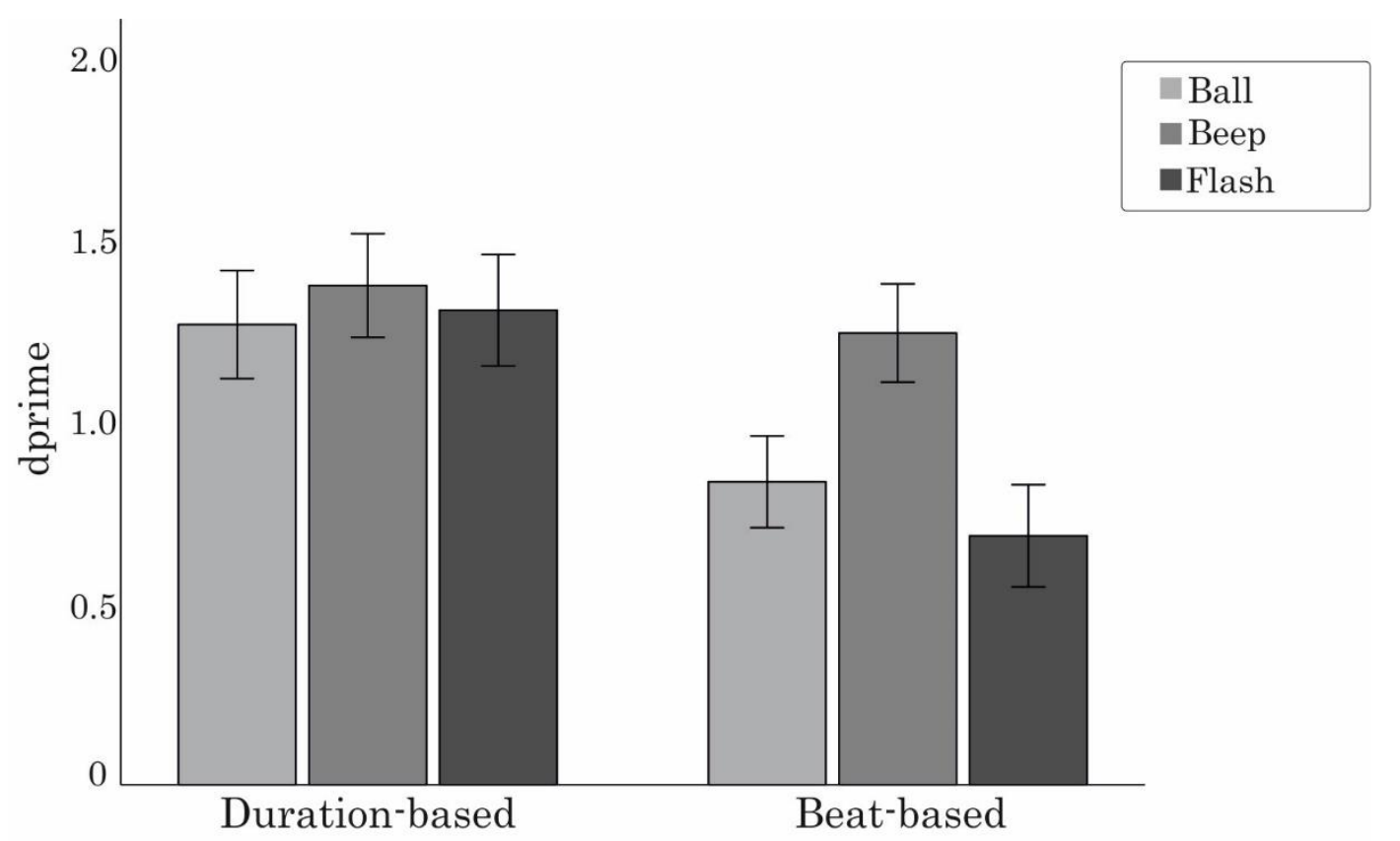

Figure 4. Discrimination between speed up and slow down sequences (Duration-based) and correct and incorrect sequences (Beat-based) as a function of Stimulus Type (auditory - beep; moving visual - ball; static visual - flash).

\subsection{Effects of Change Direction x Stimulus Type on duration-based perception}

The ANOVA showed no significant interaction between Change direction (speed up vs. slow down) and Stimulus Type on accuracy for duration-based perception, $F(2,88)=$ 
2.682, $p=.074, \eta_{\mathrm{p}}^{2}=.057$ (Figure 5). These results are in line with the discrimination analysis (cf. 2.1), indicating that Stimulus Type has no effect on duration-based perception.

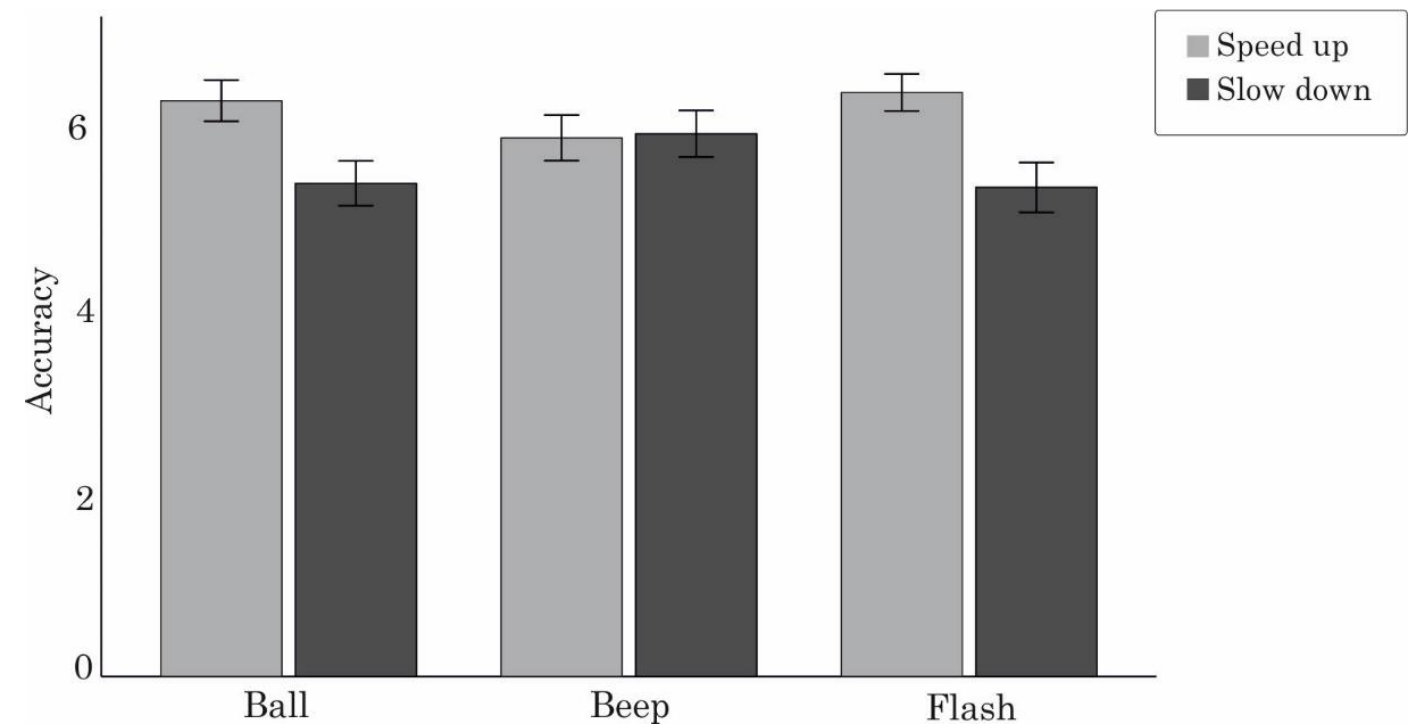

Figure 5. Accuracy for speed up vs. slow down sequences across the three types of stimulus (ball, beep and flash). The interaction between Change Direction (speed up vs. slow down) and Stimulus Type was nonsignificant.

\subsection{Effects of Deviation Type and Stimulus Type on Beat-based perception}

The ANOVA showed no significant interaction between Deviation Type (type 1 vs. type 2, see Stimuli and Appendix 2) and Stimulus Type on correct rejections, $F(2,98)=$ 2.234, $p=.113, \eta_{\mathrm{p}}^{2}=.44$. This does not mirror the differences between Stimulus Types observed in the discrimination analysis (cf. 2.1), indicating that Error Type analyses might not be a good index of perceptual performance across Stimulus Type, in line with Silva et al. (2016).

\subsection{Correlation between Beat-based timing and Duration-based timing}

The analysis showed no significant correlation between Timing Systems (beatbased and duration-based) for any Stimulus Type level (all $p s>.080$ ). This dissociation converges with the differences between timing systems observed in the discrimination analysis (2.1). 


\section{Correlations between synchronization and perception}

Synchronization stability did not correlate with the d-prime values of durationbased or beat-based perceptual tasks (all $p s>.360$ ), except flashes in duration-based timing, which correlated moderately with flash in synchronization stability $(\mathrm{r}=.357, p=$ $.048)$.

4. Correlations between musical expertise, synchronization stability and perceptual discrimination

The number of years of musical training did not correlate significantly either with perceptual discrimination (all $p \mathrm{~s}>.061$ ) or with synchronization stability (all $p \mathrm{~s}>.068$ ). 


\section{Discussion}

It was known that moving visual stimuli (bouncing balls) hold an advantage over static visual ones (flashes) in sensorimotor synchronization, such that the former match auditory beeps in driving synchronization, while the latter do not. It was also known that this occurs in beat-based synchronization, but not in beat-based purely perceptual tasks, suggesting that the advantage is action-specific. The main goal of this study was to test for the advantage of moving over static visual stimuli in a different perceptual timing system duration-based perception, so as to determine if the advantage is action-specific in a broad sense, i.e., if it excludes both beat-based and duration-based perception. In order to accomplish this goal, we compared the discrimination performance of a single group of participants in two perceptual tasks, involving beat-based timing and duration-based timing, and dealing with moving visual (bouncing balls), static visual (flashes) and auditory stimuli (beeps). As a subsidiary goal, we wanted to first replicate previous findings of Silva et al. (2016), indicating that moving visual stimuli outperform static ones in synchronization, but not in beat-based performance.

Concerning our subsidiary goal, synchronization results replicated Silva et al.'s (2016) findings. Balls not only outperformed flashes, but they also matched beeps in all measures of stability and error correction. Discrimination measures from the purely perceptual task for beat-based timing also replicated Silva et al.'s (2016) findings, in that moving visual stimuli (balls) were as insufficient as static ones (flashes) to facilitate discrimination between correct and incorrect versions, and both were less efficient than beeps. Thus, continuous movement does not seem sufficient to make visual stimuli as efficient as auditory ones in beat-based perception (Grahn, Henry, McAuley, 2010; Pasinski, MacAuley, Snyder, 2015; Silva et al, 2016).

The increased temporal sensitivity in audition relative to vision in beat-based perception may be due a privileged capability of the auditory modality for time quantification (Merchant, 2014; Rammsayer, 2014). According to a central clocking model of timing perception, a pacemaker generates pulses that accumulate in a counter, and the number of pulses that an interval generates is the internal representation of this interval. The more pulses generated, better the representation of this interval and the perception of it length (Grondin, 2010; Merchant, 2014). Thus, it is possible that beat-based auditory intervals generate more pulses and yield finer temporal resolution than visual ones. 
Overall, these findings extend those of Silva et al. (2016), who found dissociation between beat-based synchronization and perception, and ruled out the possibility that movement serves to compensate temporal-resolution problems in vision. The authors argued that the advantage of moving over static visual stimuli is tightly related to action, which is in line with evidence that synchronization improves when response taps are compatible of the spatial trajectories of moving visual stimuli (Hove and Keller, 2010; Hove et al., 2010).

Concerning our main goal, we saw no differences among balls, beeps and flashes in discrimination for duration-based perceptual timing, indicating that the advantage of moving over static visual stimuli is absent in both beat-based and duration-based perceptual systems, and seems, thus, to be action-specific in a broad sense. In addition, the effects of speed up vs. slow down sequences did not indicate any differences between moving and static visual stimuli either.

Besides not showing an advantage of moving over static visual stimuli, durationbased perception did not show modality effects - in contrast to beat-based perception, where beeps outperformed both balls and flashes. This raises interesting new questions on why modality and continuity are irrelevant in duration-based perception, and, above all, it strengthens the dissociation between beat-based and duration-based perceptual systems. The absence of correlation in performance across the two perceptual systems was consistent with this picture, also pointing to the dissociation between beat-based timing and duration-based timing that has been highlighted in research (Keele, Nicoletti, Ivry, \& Pokorny; 1989; MacAuley \& Jones, 2003; Pashler, 2001; Teki et al, 2011).

The main finding of this study was that the advantage of moving over static visual stimuli is broadly action-specific, since it is absent in perception, whatever the timing system. From a different viewpoint, our results strengthen the dissociation between production and perception (Fujii and Schlaug, 2013), since synchronization (production) differed from perception in both mechanisms, beat-based and duration-based.

Our study has a number of limitations, but also affords new insights that motivate future research. One limitation relates to the equivalence between our beat-based and duration-based tasks. Despite our efforts in creating stimuli with appropriate structures for each perceptual timing system, we cannot completely rule out that the dissociation between the two perceptual timing systems was partly due the differences in stimulus structure and complexity in the two tasks. 
To the best of our knowledge, no experimental study had yet compared the advantage of moving over static visual stimuli across synchronization, duration-based timing and beat-based timing. Thus, our study is precursor in assessing performance differences as a function of sensory modality (auditory $\mathrm{x}$ visual), continuity (moving $\mathrm{x}$ static), timing (synchronization x perception) and perceptual timing (duration-based $\mathrm{x}$ beatbased).

Studies in timing are relevant to the field of psychiatry and neurology. Patients who suffer from schizophrenia (Carrol, O’Donnell, Shekhar, \& Hetrick, 2009; Peterburs, Nitsch, Miltner \& Straube, 2013; Thoenes \& Oberfeld, 2017) and Parkinson's disease (Biswas, Hedge, Jhunjhunwal, \& Pal, 2016; Grahn \& Brett, 2009) often show problems of distorted perception or problems for processing time. Increased knowledge on healthy time perception is important to devise new assessment tools and rehabilitation programs for these populations. 


\section{Conclusion}

Among the explosion of research in timing, our study was a novel in testing modality $\mathrm{x}$ continuity interactions in two different perceptual timing systems. Our findings suggest that the advantage of moving over static visual stimuli relates to action rather than perception (Silva et al., 2016) in a broad sense, in that it is absent in both beat-based and duration-based perception. Our findings also contribute to strengthen the emergent dissociation between beat-based timing and duration-based timing (Teki et al., 2011) and sensory modality effects in temporal perception (Rammsayer, 2014).

\section{Funding}

This work has been partly funded by Fundação para a Ciência e a Tecnologia, under grant UID/PSI/00050/2013. 


\section{References}

Berens, P. (2009). CircStat: a MATLAB toolbox for circular statistics. J. Stat. Softw. 31, 121. doi: 10.18637 jss.vo31.i10

Biswas, A., Hedge, S., Jhunjhunwala, K., Pal, P. K. (2016). Two sides of the same coin: Impairment in perception of temporal components of rhythm and cognitive functions in Parkinson's disease. Basal Ganglia. 6, 63-70. doi: 10.1016/j.baga.2015.12.001

Chen, Y., Repp, B.H., \& Patel, A.D. (2002). Spectral decomposition of variability in synchronization and continuation tapping: comparisons between auditory and visual pacing and feedback conditions. Hum. Mov. Sci. 21, 515-532. doi: 10.1016/S01679457(02)00138-0

Chen, J. L., Penhune, V. B., \& Zatorre, R. J. (2008). Moving on time: brain network for auditory-motor synchronization is modulated by rhythm complexity and musical training. Journal of Cognitive Neuroscience. 20(2), 226-239. doi: 10.1162/jocn.2008.20018

Carroll, C. A., O’Donnell, B. F., Shekhar, A., Hetrick, W. P. (2009). Timing dysfunctions in schizophrenia span from millisecond to several-second durations. Brain and Cognition. 70, 181-190. doi: 10.1016/j.bandc.2009.02.001.

Fujii, S., Schlaug, G. (2013). The Harvard Beat Assessment Test (H-BAT): a battery for assessing beat perception and production and their dissociation. Front. Hum. Neurosci. 7, 771. doi: 10.33.89/fnhum.2013.00771

Gan, L., Huang, Y., Zhou, L., Qian, C., \& Wu, X. (2015). Synchronization to a bouncing ball with a realistic motion trajectory. Scientific Reports. 5. doi: 10.1038/srep11974

Glenberg, A.M., Jona, M. (1991). Temporal coding in rhythm tasks revealed by modality effects. Memory \& Cognition. 19(5), 514-522. doi: 10.3758/BF03199576

Grahn, J. A., Henry, M. J., \& Mcauley, J. D. (2010). fMRI investigation of cross-modal interactions in beat perception: auditions primes vision, but not vice versa. NeuroImage. 54, 1231-1243. doi: 10.1016/j.neuroimage.2010.09.033

Grahn, J. A., Brett, M. (2009). Impairment of beat-based rhythm discrimination in Parkinson's disease. Cortex. 45, 54-61. doi: 10.1016/j.cortex.2008.01.005

Grahn, J. A., Henry, M. J., McAuley, J. D. (2011). FMRI investigation of cross-modal interactions in beat perception: Audition primes vision, but not vice versa. NeuroImage. 54(2), 1231-1243. doi: 10.1016/j.neuroimage.2010.09.033 
Grahn, J. A. (2012). See what I hear? Beat perception in auditory and visual rhythms. Exp Brain Re. 220, 51-61. doi: 10.1007//s0021-012-3114-8

Grondin, S. (2010). Timing and time perception: A review of recent behavioral and neuroscience findings and theoretical directions. Attention, Perception \& Psychophysics. 72 (3), 561-582. doi: 10.3758/APP.72.3.561

Grube, M., Lee, K. H., Griffiths, T., Barker, A., Woodruff, P. (2010). Transcranial Magnetic Theta-Burst Stimulation of the Human Cerebellum Distinguishes Absolute, Duration-Based from Relative, Beat-Based Perception of Subsecond Time Intervals. Frontiers in Psychology. 1, 171. doi: 10.3389/fpsyg.2010.00171

Guttman, S. E., Gilroy, L. A., \& Blake, R. (2005). Hearing What the Eyes See: Auditory Encoding of Visual Temporal Sequences. Psychological Science. 16(3), 228-235. doi: 10.1111/j.0956-7976.2005.00808.x

Hove, M. J., Keller, P. E. (2010). Spatiotemporal relations and movement trajectories in visuomotor synchronization. Music Percept. 28, 15-26. doi : 10.1525/mp.2010.28.1.15

Hove, M. J., Fairhurst, M. T., Kotz, S. A., \& Keller, P. E. (2013). Synchronizing with auditory and visual rhythms: an fMRI assessment of modality differences and modality appropriateness. NeuroImage. 67, 313-321. doi: 10.1016/j.neuroimage.2012.11.032

Hove, M. J., Iversen, J. R., Zhang, A., Repp, B. H. (2013). Synchronization with competing visual and auditory rhythms: bouncing ball meets metronome. Psychological Research. 77, 388-398. doi: 10.1007/s00426-012-0441-0

Hove, M. J., Spivey, M. J., \& Krumhansl, C. (2010). Compatibility of motion facilitates visuomotor synchronization. Journal of Experimental Psychology: Human Perception And Performance. 36, 1525-1534. doi: 10.1037/a0019059

Iversen, J. R., Patel, A. D., Nicodemus, B., \& Emmorey, K. (2015). Synchronization to auditory and visual rhythms in hearing and deaf individuals. Cognition. 134, 232244. doi: 10.1016/j.cognition.2014.10.018

Keele, S. W., Nicoletti, R., Ivry, R. I., Pokorny, R. A. (1989). Mechanisms of perceptual timing: Beat-based or interval-based judgements? Psychological Research. 50, 251256. doi: 10.1007/BF00309261

Mcauley, J. D., \& Jones, M. R. (2003). Modeling effects of rhythmic context on perceived duration: a comparison of interval and entrainment approaches to short-interval 
timing. J. Exp. Psychol. Hum. Percept. Perform. 29, 1102-1125. doi: 10.103//00961523.29.6.1102

Merchant, H., Lafuente, V.de. (2014). Neurobiology of interval timing. (1a ed.) New York: Springer.

Pashler, H. (2001). Perception and production of brief durations: Beat-based versus interval-based timing. J. Exp. Psychol. Hum. Percept. Perfor. 27, 485-493. doi: 10.1037

Pasinski, A. C., McAuley, D., Snyder, J. S. (2016). How modality specific is processing of auditory and visual rhythms? Psychophysiology. 53, 198-208. doi: 10.1111/psyp.12559

Patel, A. D., Iversen, J. R., Chen, Y., \& Repp, B. H. (2005). The influence of metricality and modality on synchronization with a beat. Exp. Brain. Res. 163, 226-238. doi: $10.1007 / \mathrm{s} 00221-004-2159-8$

Peterburs, J., Nitsch, A. M., Miltner, W. H. R, Straube, T. (2013). Impaired Representation of Time in Schizophrenia Is Linked to Positive Symptoms and Cognitive Demand. PLoS ONE. 8(6), 615. doi: 10.1371/journal.pone.0067615

Pollok, B., Krause, V., Butz, M., \& Schinitzler, A. (2009). Modality specific functional interaction in sensorimotor synchronization. Hum. Brain Mapp. 30, 1783-1790. doi: $10.1002 / \mathrm{hbm} .20762$

Rammsayer, T. H. (2014). The effects of type interval, sensory modality, base duration, and psychophysical task on the discrimination of brief time intervals. Atten Percept Psychophys. 76, 1185-1196. doi: 10.3758/s13414-014-0655-x

Repp, B. H. (2005). Sensorimotor synchronization: a review of the tapping literature. Psychonomic Bulletin \& Review. 12, 969-992. doi: 10.3758/BF03206433

Repp, B. H., \& Panel, A. (2002). Auditory dominance in temporal processing: new evidence from synchronization with simultaneous visual and auditory sequences. Journal of Experimental Psychology: Human Perception and Performance. 28(5), 1085-1099. doi: 10.1037/0096-1523.28.5.1085

Silva, S., \& Castro, S. L. (2016). Moving stimuli facilitate synchronization but not temporal perception. Frontiers in Psychology. 7, 1798 . doi: 10.3389/fpsyg.2016.01798

Stanislaw, H., \& Todorov, N. (1999). Calculation of signal detection theory measures. Behav. Res. Methods Instrum Comput.31, 137-149. doi: 10.3758/BF03207704 
Stauffer, C. C.,Haldemann, J., Troche, S. J., \& Rammsayer, T. H. Auditory and visual temporal sensitivity: evidence from hierarchical structure of modality-specific and modality-independent levels of temporal information processing. Psychological research. 76, 20-31. doi: 10.1007/s004426-011-0333-8

Su, Y.-H. (2014). Audiovisual beat induction in complex auditory rhythms: Point-light figure movement as an effective visual beat. Acta Psychologica. 151, 40-50. doi: 10.1016/j.actpsy.2014.05.016

Teki, S., Grube, M., Kumar, S., \& Griffiths, T. D. (2011). Distinct neural substrates of duration-based and beat-based auditory timing. The Journal of Neuroscience. 31, 3805-3812. doi: 10.1523/JNEUROSCI.5561-10.2011

Thoenes, S., \& Oberfeld, D. (2017). Meta-analysis of time perception and temporal processing in schizophrenia: Differential effects on precision and accuracy. Clinical Psychology Review. 54, 44-64. doi: 10.1016/j.cpr.2017.03.007

Yee, W., Holleran, S., \& Jones, M. R. (1994). Sensitivity to event timing in regular and irregular sequences: influences of musical skill. Perception \& Psychophysics. 56(4), 461-471. doi: 10.3758/BF03206737 


\section{Appendix}

APPEENDIX 1 - Stimulus sequences for speed up and slow down (values in ms)

\begin{tabular}{|c|c|c|c|c|c|c|c|c|c|}
\hline & Type & Interval 1 & Interval 2 & Difference & & Type & Interval 1 & Interval 2 & Difference \\
\hline 1 & Slow down & 300 & 433 & -133 & 9 & Speed up & 433 & 300 & 133 \\
\hline 2 & Speed up & 300 & 167 & 133 & 10 & Slow down & 167 & 300 & -133 \\
\hline 3 & Speed up & 467 & 433 & 34 & 11 & Slow down & 433 & 467 & -34 \\
\hline 4 & Speed up & 733 & 167 & 566 & 12 & Slow down & 167 & 733 & -566 \\
\hline 5 & Slow down & 300 & 467 & -167 & 13 & Speed up & 467 & 300 & 167 \\
\hline 6 & Speed up & 433 & 133 & 300 & 14 & Slow down & 133 & 433 & -300 \\
\hline 7 & Speed up & 467 & 300 & 167 & 15 & Slow down & 300 & 467 & -167 \\
\hline 8 & Speed up & 733 & 433 & 300 & 16 & Slow down & 433 & 733 & -300 \\
\hline
\end{tabular}


APPENDIX 2 - Stimulus sequences (IOIs) for error detection task

\begin{tabular}{|c|c|c|c|}
\hline & Error type & Intervals correct version (ms) & Intervals incorrect versions (ms) \\
\hline 1 & Type 1 & $\begin{array}{l}600-600-600-600-600-600- \\
600-600-300-300-(600)\end{array}$ & $\begin{array}{l}600-600-600-600-600-600-600- \\
600-433-(467)\end{array}$ \\
\hline 2 & Type 1 & $\begin{array}{l}600-600-600-600-600-600- \\
300-300-(600)\end{array}$ & $\begin{array}{l}\text { 600-600-600-600-600-600-300- } \\
167-(733)\end{array}$ \\
\hline 3 & Type 1 & $\begin{array}{l}600-600-600-600-600-600- \\
600-300-300-(600)\end{array}$ & $\begin{array}{l}600-600-600-600-600-600-600- \\
433-(467)\end{array}$ \\
\hline 4 & Type 1 & $\begin{array}{l}\text { 600-600-600-600-600-300- } \\
(600)\end{array}$ & $600-600-600-600-600-167-(733)$ \\
\hline 5 & Type 2 & $\begin{array}{l}600-600-600-600-600-600- \\
600-600-600-300-(300)\end{array}$ & $\begin{array}{l}600-600-600-600-600-600-600- \\
600-600-467-433-(300)\end{array}$ \\
\hline 6 & Type 2 & $\begin{array}{l}600-600-600-600-600-600- \\
600-600-(300)\end{array}$ & $\begin{array}{l}600-600-600-600-600-600-600- \\
600-733-167-(300)\end{array}$ \\
\hline 7 & Type 2 & $\begin{array}{l}600-600-600-600-600-600- \\
600-300-(300)\end{array}$ & $\begin{array}{l}600-600-600-600-600-600-600- \\
467-433-(300)\end{array}$ \\
\hline 8 & Type 2 & $\begin{array}{l}\text { 600-600-600-600-600-600- } \\
(300)\end{array}$ & $\begin{array}{l}600-600-600-600-600-600-733- \\
167-(300)\end{array}$ \\
\hline
\end{tabular}

Numbers in italic indicate that were changed in incorrect versions. The final interval is indicated in parenthesis since it has an undefined end point (the end of the stimulus). 